\title{
Condorcet Consistency and the strong no show paradoxes
}

Citation for published version (APA):

Kasper, L., Peters, H., \& Vermeulen, D. (2017). Condorcet Consistency and the strong no show paradoxes. Maastricht University, Graduate School of Business and Economics. GSBE Research Memoranda No. 017 https://doi.org/10.26481/umagsb.2017017

Document status and date:

Published: 25/06/2017

DOI:

10.26481/umagsb.2017017

Document Version:

Publisher's PDF, also known as Version of record

\section{Please check the document version of this publication:}

- A submitted manuscript is the version of the article upon submission and before peer-review. There can be important differences between the submitted version and the official published version of record.

People interested in the research are advised to contact the author for the final version of the publication, or visit the DOI to the publisher's website.

- The final author version and the galley proof are versions of the publication after peer review.

- The final published version features the final layout of the paper including the volume, issue and page numbers.

Link to publication

\footnotetext{
General rights rights.

- You may freely distribute the URL identifying the publication in the public portal. please follow below link for the End User Agreement:

www.umlib.nl/taverne-license

Take down policy

If you believe that this document breaches copyright please contact us at:

repository@maastrichtuniversity.nl

providing details and we will investigate your claim.
}

Copyright and moral rights for the publications made accessible in the public portal are retained by the authors and/or other copyright owners and it is a condition of accessing publications that users recognise and abide by the legal requirements associated with these

- Users may download and print one copy of any publication from the public portal for the purpose of private study or research.

- You may not further distribute the material or use it for any profit-making activity or commercial gain

If the publication is distributed under the terms of Article $25 \mathrm{fa}$ of the Dutch Copyright Act, indicated by the "Taverne" license above, 


\section{Maastricht University}

Laura Kasper, Hans Peters,

Dries Vermeulen

Condorcet Consistency and the strong no show paradoxes

$\mathrm{RM} / 17 / 017$

\section{GSBE}

Maastricht University School of Business and Economics

Graduate School of Business and Economics

P.O Box 616

NL- 6200 MD Maastricht

The Netherlands 


\title{
Condorcet Consistency and the strong no show paradoxes
}

\author{
Laura Kasper* Hans Peters ${ }^{\dagger} \quad$ Dries Vermeulen ${ }^{\ddagger}$
}

June 2017

\begin{abstract}
We consider voting correspondences that are, besides Condorcet Consistent, immune against the two strong no show paradoxes. That is, it cannot happen that if an additional voter ranks a winning alternative on top then that alternative becomes loosing, and that if an additional voter ranks a loosing alternative at bottom then that alternative becomes winning. This immunity is called the Top Property in the first case and the Bottom Property in the second case. We establish the voting correspondence satisfying Condorcet Consistency and the Top Property, which is maximal in the following strong sense: it is the union of all smaller voting correspondences with these two properties. The result remains true if we add the Bottom Property but not if we replace the Top Property by the Bottom Property. This voting correspondence contains the Minimax Rule but it is strictly larger. In particular, voting functions (single-valued voting correspondences) that are Condorcet Consistent and immune against the two paradoxes must select from this maximal correspondence, and we demonstrate several ways in which this can or cannot be done.
\end{abstract}

Keywords Voting, Condorcet Consistency, strong no show paradoxes, Minimax Rule

JEL-classification D71, D72

\footnotetext{
* Maastricht University and Saarland University, 1.kasper@maastrichtuniversity.n]

${ }^{\dagger}$ Maastricht University, h.peters@maastrichtuniversity.nl

${ }^{\ddagger}$ Maastricht University, d.vermeulen@maastrichtuniversity.nl
} 


\section{Introduction}

Within a democratic voting system it should be in the own interest of voters not to abstain from voting. Abstaining from voting, however, can be rational even in voting systems that are often regarded as truly democratic. A recent example is the Dutch referendum for the EU Association Treaty with the Ukraine on April 6, 2016. A majority voted against this treaty, but the total voter turnout was hardly more than $2 \%$ above the minimally required $30 \%$ : if some of the 'yes' voters would have stayed at home then the referendum would have been invalid and the 'no' to the treaty avoided.

Another natural and desirable property of a voting system is Condorcet Consistency (de Condorcet, 1785): if there is an alternative (candidate, political party, law, etc.) that is ranked above any other alternative by some majority of the voters, then that alternative should be chosen. Also this property is often not fulfilled. Again in The Netherlands, van Deemen and Vergunst (1998) provide evidence that D66 (a progressive liberal party) may have been the Condorcet winner in several consecutive Dutch elections for Parliament, but it never won those elections and, consequently, could never take the lead in the formation of a new government.

In this paper we study voting correspondences which are Condorcet Consistent and which do not admit situations where ranking one's favorite alternative first may turn this alternative from a winner into a looser, or ranking one's least favorite alternative last may turn this from a looser into a winner - in the two-alternative referendum on the Ukraine Association treaty mentioned above both these situations occurred. In Nurmi (2002) and Pérez (2001) these phenomena are referred to as the positive and negative strong no show paradoxes, respectively. Recently, Felsenthal and Nurmi (2016) investigated a number of well-known Condorcet Consistent voting correspondences with respect to the occurrence of these two paradoxes. They find that the Minimax Rule rules out both. The Minimax Rule chooses those alternatives for which a minimal number of voters rank some other alternative higher.

We call the avoidance of these paradoxes the Top Property and the Bottom Property, respectively. Thus, the Top Property says that if an additional voter ranks a winning alternative on top then that alternative remains winning, and the Bottom Property says that if an additional voter ranks a loosing alternative at bottom then that alternative remains loosing. As one of the main results in the paper we establish the maximal Condorcet Consistent voting correspondence $H$ that satisfies the Top Property, that is: each Condorcet Consistent voting correspondence satisfying the Top Property must be contained in $H$ and, a fortiori, $H$ is the union of all smaller voting correspondences with the two properties. We also show that this result remains true if we add the Bottom Property, but not if we replace the Top Property by the Bottom Property. The Minimax Rule in particular is contained in $H$. Furthermore, we show that also voting functions (single-valued or resolute voting correspondences) that are Condorcet Consistent (i.e., they choose a Condorcet winner if there is one) and rule out both paradoxes must select from $H$, and we exhibit several ways in 
which this can or cannot be done.

Moulin (1988) shows that if there are at least four alternatives and at least twenty-five voters, no Condorcet Consistent voting function can satisfy a condition called 'participation': this condition requires that no voter can be worse off by voting than by abstention. The participation condition rules out the no show paradox as formulated in Brams and Fishburn (1983). This no show paradox is weaker (hence, occurs more often) than the combination of the two strong versions that we consider and, consequently, the participation condition in Moulin (1988) is stronger than the combination of the Top Property and the Bottom Property. See also Jimeno et al (2009), Brandt et al (2017), and Núñez and Sanver (2017) for extensions and strengthenings of the results in Moulin (1988) on the (weak) no show paradox; and Felsenthal and Tideman (2013) and Duddy (2014) on the strong no show paradoxes. In particular, Duddy (2014) allows weak preference rankings and shows that then every Condorcet consistent voting function must exhibit both paradoxes if there are at least four alternatives. We consider linear orderings, that is, strict rankings.

In Section 2 of the paper we provide basic concepts and definitions, and in Section 3 we consider voting correspondences. Our main result is Corollary 3.8 , which states that the correspondence $H$ alluded to above is the maximal voting correspondence that is Condorcet Consistent and satisfies both the Top Property and Bottom Property. In Section 4 we consider voting functions with these properties, which are necessarily selections from $H$. We may, in particular, choose from the Minimax Rule according to a fixed tie-breaking ordering, but this result does not extend to $H$. Section 5 concludes. Some of the proofs are relegated to the Appendix.

\section{Basic definitions}

We let $A$ denote the finite set of alternatives. The set of potential voters is $\mathbb{N}$. A ranking is a linear ordering (reflexive, complete, transitive, and antisymmetric) over $A$, and $L$ denotes the set of rankings. For a finite set $N \subseteq \mathbb{N}, R^{N}=$ $\left(R^{i}\right)_{i \in N} \in L^{N}$ is called a profile. For $j \in \mathbb{N} \backslash N$ and $R^{j} \in L$ we typically denote by $\left(R^{N}, R^{j}\right)$ a profile where each $i \in N$ has ranking $R^{i}$ and $j$ has ranking $R^{j}$. Also, for $R^{\prime} \in L,\left(R^{N}, R^{\prime}\right)$ denotes a profile for $N$ and an additional voter with ranking $R^{\prime}$. For a ranking $R$ we denote by $t(R)$ its top alternative and by $b(R)$ its bottom alternative, that is, $t(R) R x R b(R)$ for all $x \in A$.

For two distinct alternatives $x$ and $y$,

$$
n_{x y}\left(R^{N}\right)=\left|\left\{i \in N: x R^{i} y\right\}\right|-\left|\left\{i \in N: y R^{i} x\right\}\right|
$$

denotes the net number of voters ranking $x$ over $y$. Clearly, $n_{x y}\left(R^{N}\right)=-n_{y x}\left(R^{N}\right)$. The number

$$
m_{x}\left(R^{N}\right)=\max _{y \in A \backslash\{x\}} n_{y x}\left(R^{N}\right)
$$

is called the (maximal) resistance against $x$. Note that $n_{x y}\left(R^{N}\right)$ and $m_{x}\left(R^{N}\right)$ have the same parity (odd or even) as $|N|$. 
An alternative $x$ is a (weak) Condorcet winner at $R^{N}$ if $m_{x}\left(R^{N}\right) \leq 0$ or, equivalently, $n_{x y}\left(R^{N}\right) \geq 0$ for all $y \in A \backslash\{x\}$. The (possibly empty) set of Condorcet winners is denoted by $\mathcal{C}\left(R^{N}\right)$, hence

$$
\mathcal{C}\left(R^{N}\right)=\left\{x \in A: m_{x}\left(R^{N}\right) \leq 0\right\} .
$$

Remark 2.1. Clearly, if $m_{x}\left(R^{N}\right)<0$ for some $x \in A$, then $n_{y x}\left(R^{N}\right)<0$ for all $y \in A \backslash\{x\}$, which in turn implies $n_{x y}\left(R^{N}\right)>0$ and thus $m_{y}\left(R^{N}\right)>0$ for all $y \in A \backslash\{x\}$. Therefore, $\mathcal{C}\left(R^{N}\right)=\{x\}$. In this case, $x$ is the unique Condorcet winner, usually called the strong Condorcet winner.

A voting correspondence $C$ assigns to each profile $R^{N}$ a nonempty subset $C\left(R^{N}\right)$ of $A$, and a voting function $F$ assigns to each profile $R^{N}$ an alternative $F\left(R^{N}\right) \in A$. If $F\left(R^{N}\right) \in C\left(R^{N}\right)$ for each profile $R^{N}$, then we call (voting function) $F$ a selection from (voting correspondence) $C$.

\section{Condorcet Consistency, Top Property, and Bot- tom Property for voting correspondences}

Let $C$ be a voting correspondence. The following properties are of central interest in this paper.

Condorcet Consistency (CC) For every profile $R^{N}$ such that $\mathcal{C}\left(R^{N}\right) \neq \emptyset$, $C\left(R^{N}\right)=\mathcal{C}\left(R^{N}\right)$.

Top Property (TP) For every profile $R^{N}$, every $j \in \mathbb{N} \backslash N$, every $x \in A$, and every $R^{j}$ with $t\left(R^{j}\right)=x$, if $x \in C\left(R^{N}\right)$, then $x \in C\left(R^{N}, R^{j}\right)$.

Bottom Property (BP) For every profile $R^{N}$, every $j \in \mathbb{N} \backslash N$, every $x \in A$, and every $R^{j}$ with $b\left(R^{j}\right)=x$, if $x \notin C\left(R^{N}\right)$, then $x \notin C\left(R^{N}, R^{j}\right)$.

Condorcet Consistency says that if there exist Condorcet winners, then exactly those should be chosen. The two other properties guarantee that the following two situations cannot occur. First, if $x$ is chosen and an additional voter ranks $x$ at top, then $x$ is no longer chosen; second, if $x$ is not chosen and an additional voter ranks $x$ at bottom, then $x$ is chosen. Thus, in theses cases, the additional voter would be better off by abstention. The Top Property and the Bottom Property prevent exactly these so-called strong no show paradoxes.

Remark 3.1. The requirement of Condorcet Consistency can be subject to discussion in some situations. Suppose, of 99 voters, 50 rank $a$ on top, $b$ second, and all other candidates below $a$ and $b$. The remaining 49 voters rank $b$ on top and $a$ last. Then $a$ is the (unique, strong) Condorcet winner but one could argue that $b$ is a much better compromise.

A main goal of this paper is to investigate which voting correspondences satisfy all three properties. A first result concerns the Minimax Rule, which 
dates back to Black (1958), Simpson (1969), and Kramer (1977). The Minimax Rule $M$ is defined by

$$
M\left(R^{N}\right)=\left\{x \in A: m_{x}\left(R^{N}\right) \leq m_{y}\left(R^{N}\right) \text { for all } y \in A\right\}
$$

hence it chooses those alternatives against wich resistance is minimal.

The following result is already known (e.g., Felsenthal and Nurmi, 2016; Felsenthal and Tideman, 2013; and Pérez, 2001), but for completeness we provide a proof in the Appendix.

Proposition 3.2. $M$ satisfies $C C$, $T P$, and $B P$.

Until further notice we concentrate on CC and TP, and investigate if it is possible to choose alternatives additional to those in $M$ without violating TP. The following example may be instructive.

Example 3.3. Let $A=\{a, b, c\}$ and consider the 10 -voter profile $R^{N}$ given by

\begin{tabular}{lll}
3 & 3 & 4 \\
\hline$a$ & $b$ & $c$ \\
$b$ & $c$ & $a$ \\
$c$ & $a$ & $b$
\end{tabular}

where the first column indicates that three voters have ranking $R$ with $a R b R c$, also denoted as $R=a b c$; etc. The table of pairwise comparisons is

\begin{tabular}{c|ccc} 
& $a$ & $b$ & $c$ \\
\hline$a$ & - & 7 & 3 \\
$b$ & 3 & - & 6 \\
$c$ & 7 & 4 & -
\end{tabular}

For instance, the number 7 in row $a$ and column $b$ means that seven voters rank $a$ above $b$. Hence $n_{a b}\left(R^{N}\right)=7-3=4, n_{a c}\left(R^{N}\right)=-4$, and $n_{b c}\left(R^{N}\right)=2$. Then $m_{a}\left(R^{N}\right)=m_{b}\left(R^{N}\right)=4$ and $m_{c}\left(R^{N}\right)=2$, so that $\mathcal{C}\left(R^{N}\right)=\emptyset$ and $M\left(R^{N}\right)=\{c\}$.

Could we, additionally to $c$, also choose $a$ ? If we add two voters who rank $a$ on top and $c$ second, then $c$ becomes a Condorcet winner, but not $a$ :

\begin{tabular}{cccc}
3 & 3 & 4 & 2 \\
\hline$a$ & $b$ & $c$ & $a$ \\
$b$ & $c$ & $a$ & $c$ \\
$c$ & $a$ & $b$ & $b$
\end{tabular}

\begin{tabular}{c|ccc} 
& $a$ & $b$ & $c$ \\
\hline$a$ & - & 9 & 5 \\
$b$ & 3 & - & 6 \\
$c$ & 7 & 6 & -
\end{tabular}

Now $\mathrm{CC}$ requires $c$ to be chosen uniquely, and this violates $T P$ since $a$ is no longer chosen.

This cannot happen if $b$ is chosen additionally to $c$, since adding rankings with $b$ on top will imply that $b$ keeps on beating $c$ by majority, so that $c$ cannot 
become a Condorcet winner. Indeed, adding (e.g.) four voters with ranking bac to the original profile results in:

\begin{tabular}{|c|c|c|c|c|c|c|c|}
\hline 3 & 3 & 4 & 4 & & $a$ & $b$ & $c$ \\
\hline$a$ & $b$ & $c$ & $b$ & $a$ & - & 7 & 7 \\
\hline$b$ & $c$ & $a$ & $a$ & $b$ & 7 & - & 10 \\
\hline$c$ & $a$ & $b$ & $c$ & $c$ & 7 & 4 & - \\
\hline
\end{tabular}

so that $a$ and $b$ are both Condorcet winners, and $b$ remains to be chosen.

What we learn from this example is the following. If $x$ and $y$ are alternatives and, at some profile $R^{N}$ without Condorcet winners, we have $m_{y}\left(R^{N}\right)<$ $m_{x}\left(R^{N}\right)$, then choosing $x$ and adding rankings with $x$ on top and (as worst case) $y$ second may cause $y$ to become a Condorcet winner before $x$, unless already at $R^{N}, x$ has sufficient support against $y$ : we need that $n_{x y}\left(R^{N}\right)>-m_{y}\left(R^{N}\right)$, since then $y$ can never become a Condorcet winner by adding rankings with $x$ on top. This condition is equivalent to the condition $n_{y x}\left(R^{N}\right)<m_{y}\left(R^{N}\right)$. Indeed, one can indeed easily check that in Example 3.3 the inequality holds for $x=b$ and $y=c$ but not for $x=a$ and $y=c$.

These considerations lead to the following definition.

Definition 3.4. The voting correspondence $H$ is defined by

$H\left(R^{N}\right)=\left\{x \in A:\left[m_{y}\left(R^{N}\right)<m_{x}\left(R^{N}\right) \Rightarrow n_{y x}\left(R^{N}\right)<m_{y}\left(R^{N}\right)\right]\right.$ for all $\left.y \in A\right\}$ for every profile $R^{N}$.

Clearly, the implication in the definition of $H$ is trivially satisfied for alternatives $x$ against which resistance $m_{x}\left(R^{N}\right)$ is minimal, hence $M\left(R^{N}\right) \subseteq H\left(R^{N}\right)$.

We first prove the following result.

Proposition 3.5. $H$ satisfies $C C$ and $T P$.

Proof. First, we show that $H$ satisfies CC. Let $R^{N} \in L^{N}$ such that $\mathcal{C}\left(R^{N}\right) \neq$ $\emptyset$. Then $\mathcal{C}\left(R^{N}\right)=M\left(R^{N}\right) \subseteq H\left(R^{N}\right)$. Suppose that $x \in A \backslash \mathcal{C}\left(R^{N}\right)$. Take $y \in \mathcal{C}\left(R^{N}\right)$. Then $m_{y}\left(R^{N}\right) \leq 0<m_{x}\left(R^{N}\right)$. Hence $n_{x y}\left(R^{N}\right) \leq 0$, which is equivalent to $n_{y x}\left(R^{N}\right) \geq 0$. Thus, $n_{y x}\left(R^{N}\right) \geq m_{y}\left(R^{N}\right)$, so that $x \notin H\left(R^{N}\right)$.

Next we show that $\mathrm{H}$ satisfies TP. Let $R^{N}$ be a profile and $x \in A$ with $x \in H\left(R^{N}\right)$. Let $R^{\prime} \in L$ with $t\left(R^{\prime}\right)=x$. First, if $\mathcal{C}\left(R^{N}\right) \neq \emptyset$, then $H\left(R^{N}\right)=$ $\mathcal{C}\left(R^{N}\right)=M\left(R^{N}\right)$ by the first part of the proof. Then, by Proposition 3.2, $x \in$ $M\left(R^{N}, R^{\prime}\right)$, hence $x \in H\left(R^{N}, R^{\prime}\right)$ and TP is satisfied. Second, if $\mathcal{C}\left(R^{N}\right)=\emptyset$, then suppose there is $y \in A$ with $m_{y}\left(R^{N}, R^{\prime}\right)<m_{x}\left(R^{N}, R^{\prime}\right)$. We have to show that $n_{y x}\left(R^{N}, R^{\prime}\right)<m_{y}\left(R^{N}, R^{\prime}\right)$. If $m_{y}\left(R^{N}\right)<m_{x}\left(R^{N}\right)$ then $n_{y x}\left(R^{N}, R^{\prime}\right)=$ $n_{y x}\left(R^{N}\right)-1<m_{y}\left(R^{N}\right)-1 \leq m_{y}\left(R^{N}, R^{\prime}\right)$, where the strict inequality follows since $x \in H\left(R^{N}\right)$. If $m_{y}\left(R^{N}\right) \geq m_{x}\left(R^{N}\right)$ then $m_{x}\left(R^{N}, R^{\prime}\right)>m_{y}\left(R^{N}, R^{\prime}\right) \geq$ $m_{y}\left(R^{N}\right)-1 \geq m_{x}\left(R^{N}\right)-1=m_{x}\left(R^{N}, R^{\prime}\right)$, a contradiction, so this case cannot occur.

Now we show that $H$ not only satisfies CC and TP but is, moreover, the maximal voting correspondence satisfying these conditions, in the following sense. 
Proposition 3.6. Let $C$ be a voting correspondence satisfying $C C$ and TP. Then $C\left(R^{N}\right) \subseteq H\left(R^{N}\right)$ for every $R^{N} \in L^{N}$.

Proof. Let $R^{N} \in L^{N}$ and suppose that for some $x \in A$ we have $x \in C\left(R^{N}\right) \backslash$ $H\left(R^{N}\right)$. We derive a contradiction. Since $x \notin H\left(R^{N}\right)$, there is a $y \in A$ such that $m_{y}\left(R^{N}\right)<m_{x}\left(R^{N}\right)$ and $n_{y x}\left(R^{N}\right) \geq m_{y}\left(R^{N}\right)$. By CC of $C$ and $H$ we must have $m_{y}\left(R^{N}\right)>0$. Hence, $n_{y x}\left(R^{N}\right)>0$. Equivalently, $n_{x y}<0$, which implies that $m_{y}\left(R^{N}\right)=n_{\widetilde{x} y}\left(R^{N}\right)$ for some $\widetilde{x} \in A \backslash\{x\}$, i.e., $x$ does not have the maximal resistance against $y$ at the profile $R^{N}$. Let $R^{\prime} \in L$ such that $x R^{\prime} y R^{\prime} z$ for all $z \in A \backslash\{x, y\}$. Then $m_{x}\left(R^{N}, R^{\prime}\right)=m_{x}\left(R^{N}\right)-1$ and $m_{y}\left(R^{N}, R^{\prime}\right)=m_{y}\left(R^{N}\right)-1$. Thus, we still have $m_{y}\left(R^{N}, R^{\prime}\right)<m_{x}\left(R^{N}, R^{\prime}\right)$, and $n_{y x}\left(R^{N}, R^{\prime}\right)=n_{y x}\left(R^{N}\right)-1 \geq m_{y}\left(R^{N}\right)-1=m_{y}\left(R^{N}, R^{\prime}\right)$. Therefore, if we keep on adding the ranking $R^{\prime}$, then $n_{y x}\left(R^{N}, R^{\prime}, \ldots, R^{\prime}\right)$ decreases but still $n_{y x}\left(R^{N}, R^{\prime}, \ldots, R^{\prime}\right) \geq m_{y}\left(R^{N}, R^{\prime}, \ldots, R^{\prime}\right)$. Hence, after adding $m_{y}\left(R^{N}\right)$ rankings $R^{\prime}$ we have $m_{y}\left(R^{N}, R^{\prime}, \ldots, R^{\prime}\right)=0$ while $m_{x}\left(R^{N}, R^{\prime}, \ldots, R^{\prime}\right)>$ $m_{y}\left(R^{N}, R^{\prime}, \ldots, R^{\prime}\right)$. Then by CC, $y \in C\left(R^{N}, R^{\prime}, \ldots, R^{\prime}\right)$ and $x \notin C\left(R^{N}, R^{\prime}\right.$, $\left.\ldots, R^{\prime}\right)$. This violates TP of $C$.

Moreover, it turns out that $H$ also prevents the other no show paradox that we consider in this paper.

Proposition 3.7. $H$ satisfies $B P$.

Proof. Let $R^{N} \in L^{N}, R^{\prime} \in L$ with $b\left(R^{\prime}\right)=x$, and suppose that $x \in H\left(R^{N}, R^{\prime}\right)$ with $b\left(R^{\prime}\right)=x$. We show that $x \in H\left(R^{N}\right)$. Since $x \in H\left(R^{N}, R^{\prime}\right)$, for all $y \in A$ with $m_{y}\left(R^{N}, R^{\prime}\right)<m_{x}\left(R^{N}, R^{\prime}\right)$ we have $n_{y x}\left(R^{N}, R^{\prime}\right)<m_{y}\left(R^{N}, R^{\prime}\right)$, hence $n_{y x}\left(R^{N}\right)+1<m_{y}\left(R^{N}, R^{\prime}\right)$. This implies $n_{y x}\left(R^{N}\right)<m_{y}\left(R^{N}, R^{\prime}\right)-1 \leq$ $m_{y}\left(R^{N}\right)+1-1=m_{y}\left(R^{N}\right)$. Hence, $x \in H\left(R^{N}\right)$.

For voting correspondences $C$ and $C^{\prime}$ we write $C \subseteq C^{\prime}$ if $C\left(R^{N}\right) \subseteq C^{\prime}\left(R^{N}\right)$ for every profile $R^{N}$ and $C \varsubsetneqq C^{\prime}$ if $C \subseteq C^{\prime}$ and there is a profile $R^{N}$ for which $C\left(R^{N}\right) \varsubsetneqq C^{\prime}\left(R^{N}\right)$. Combining the last two propositions we obtain the following.

Corollary 3.8. $C \subseteq H$ for all voting correspondences $C$ satisfying $C C, T P$, and $B P$.

In words, $H$ is the maximal voting correspondence that is Condorcet Consistent and avoids the two strong no show paradoxes, i.e., satisfies properties BP and $\mathrm{TP}$, in the sense that it contains every other voting correspondence with these three properties. By using the following lemma we can even strengthen this result. For every $a \in A$, define the voting correspondence $C_{a}$ by

$$
C_{a}\left(R^{N}\right)=\left\{\begin{array}{cc}
M\left(R^{N}\right) & \text { if } a \notin H\left(R^{N}\right) \\
M\left(R^{N}\right) \cup\{a\} & \text { if } a \in H\left(R^{N}\right)
\end{array}\right.
$$

for every $R^{N} \in L^{N}$.

Lemma 3.9. For every $a \in A, C_{a}$ satisfies $C C, T P$, and $B P$. 
Proof. Let $a \in A$ and $R^{N} \in L^{N}$.

If $\mathcal{C}\left(R^{N}\right) \neq \emptyset$ then $H\left(R^{N}\right)=M\left(R^{N}\right)=\mathcal{C}\left(R^{N}\right)$ by Propositions 3.2 and 3.5, hence $C_{a}\left(R^{N}\right)=\mathcal{C}\left(R^{N}\right)$. This shows $\mathrm{CC}$ of $C_{a}$.

Let $x \in C_{a}\left(R^{N}\right)$ and $R^{\prime} \in L$ with $t\left(R^{\prime}\right)=x$. If $x \in M\left(R^{N}\right)$ then $x \in$ $M\left(R^{N}, R^{\prime}\right)$ by Proposition 3.2 , hence $x \in C_{a}\left(R^{N}, R^{\prime}\right)$. If $a \in H\left(R^{N}\right)$ and $x=a$, then $x=a \in H\left(R^{N}, R^{\prime}\right)$ by Proposition 3.5, hence $x \in C_{a}\left(R^{N}, R^{\prime}\right)$. Hence, $C_{a}$ satisfies TP.

Finally, suppose $y \in A$ and $y \notin C_{a}\left(R^{N}\right)$, and let $\widetilde{R} \in L$ with $y=b(\widetilde{R})$. Since $y \notin M\left(R^{N}\right)$, we have that $y \notin M\left(R^{N}, \widetilde{R}\right)$ by Proposition 3.2. If If $y \neq a$ then $y \notin C_{a}\left(R^{N}, R^{\prime}\right)$. If $y=a$ then $a \notin H\left(R^{N}\right)$ and therefore $y=a \notin H\left(R^{N}, \widetilde{R}\right)$ by Proposition 3.7, so that again $y \notin C_{a}\left(R^{N}, R^{\prime}\right)$. Hence, $C_{a}$ satisfies BP.

Corollary 3.8 and Lemma 3.9 imply that $H$ is the union of all voting correspondences $C \neq H$ satisfying $\mathrm{CC}$, TP, and BP. Thus, there is no strict subcorrespondence of $H$ that contains all voting correspondences, unequal to $H$, with these three properties.

Corollary 3.10. There is no voting correspondence $H^{\prime} \varsubsetneqq H$ such that $C \subseteq H^{\prime}$ for all voting correspondences $C \neq H$ that satisfy $C C$, TP, and BP.

From Corollary 3.8 we can drop BP but not TP. In other words, there are voting correspondences satisfying $\mathrm{CC}$ and $\mathrm{BP}$ which are not subcorrespondences of $H$. An example is the following.

Example 3.11. For a profile $R^{N} \in L^{N}$ and an alternative $x \in A$ let $\eta_{x}$ denote the minimum number of voters that have to be removed from the profile in order to make $x$ a Condorcet winner, hence

$$
\eta_{x}\left(R^{N}\right)=\arg \min \left\{\left|N^{\prime}\right|: N^{\prime} \varsubsetneqq N \text { and } x \in \mathcal{C}\left(R^{N \backslash N^{\prime}}\right)\right\} .
$$

Define the voting correspondence $Y$ (cf. Young, 1977) by

$$
Y\left(R^{N}\right)=\left\{x \in A: \eta_{x}\left(R^{N}\right) \leq \eta_{y}\left(R^{N}\right) \text { for all } y \in A\right\}
$$

for all $R^{N} \in L^{N}$. Clearly, since for each $x \in A$ we have $\eta_{x}\left(R^{N}\right)=0$ if and only if $x \in \mathcal{C}\left(R^{N}\right), Y$ is Condorcet Consistent. To show that $Y$ satisfies BP, suppose that $R^{N} \in L^{N}$ and $x \in A$ such that $x \notin Y\left(R^{N}\right)$. Let $y \in A$ with $\eta_{y}\left(R^{N}\right)<$ $\eta_{x}\left(R^{N}\right)$, and let $R^{\prime} \in L$ with $b\left(R^{\prime}\right)=x$. Then $\eta_{x}\left(R^{N}, R^{\prime}\right)=\eta_{x}\left(R^{N}\right)+1$, and therefore $\eta_{y}\left(R^{N}, R^{\prime}\right) \leq \eta_{y}\left(R^{N}\right)+1<\eta_{x}\left(R^{N}\right)+1=\eta_{x}\left(R^{N}, R^{\prime}\right)$. Hence, $x \notin Y\left(R^{N}, R^{\prime}\right)$.

In order to show that $Y$ is not a subcorrespondence of $H$, we borrow the following profile $R^{N}$ with 39 voters and 5 alternatives from Felsenthal and Nurmi (2016):

\begin{tabular}{cccccccc}
11 & 10 & 10 & 2 & 2 & 2 & 1 & 1 \\
\hline$b$ & $e$ & $a$ & $e$ & $e$ & $c$ & $d$ & $a$ \\
$a$ & $c$ & $c$ & $c$ & $d$ & $b$ & $c$ & $b$ \\
$d$ & $b$ & $d$ & $d$ & $c$ & $a$ & $b$ & $d$ \\
$e$ & $d$ & $b$ & $b$ & $b$ & $d$ & $a$ & $e$ \\
$c$ & $a$ & $e$ & $a$ & $a$ & $e$ & $e$ & $c$
\end{tabular}


It is not hard to show that $\eta_{a}\left(R^{N}\right)=17, \eta_{b}\left(R^{N}\right)=15, \eta_{c}\left(R^{N}\right)=13, \eta_{d}\left(R^{N}\right)=$ 16 , and $\eta_{e}\left(R^{N}\right)=11$, so that $Y\left(R^{N}\right)=\{e\}$. However, $m_{d}\left(R^{N}\right)=9<$ $m_{e}\left(R^{N}\right)=11$ but $n_{d e}\left(R^{N}\right)=9 \nless m_{d}\left(R^{N}\right)$, so that $e \notin H\left(R^{N}\right)$. By Proposition 3.6 this implies that $Y$ does not satisfy TP, a fact also shown by Felsenthal and Nurmi (2016) and Pérez (2001).

\section{Condorcet Consistency, Top Property, and Bot- tom Property for voting functions}

A voting function $F$ can be identified with a single-valued voting correspondence. The definitions of the Top Property and the Bottom Property therefore follow from those for a voting correspondence. The adapted definition of Condorcet Consistency is as follows.

Condorcet Consistency (CC) For every profile $R^{N}$ such that $\mathcal{C}\left(R^{N}\right) \neq \emptyset$, $F\left(R^{N}\right) \in \mathcal{C}\left(R^{N}\right)$.

We start with the following result, which still needs a proof, due to the adapted definition of CC. This proof, however, is a minor modification of the proof of Proposition 3.6, and for completeness provided in the Appendix.

Proposition 4.1. Let voting function $F$ satisfy $C C$ and TP. Then $F$ is a selection from $H$.

Thus, for a voting function to be Condorcet Consistent and satisfy the Top Property, it has to select from $H$, and the question arises how this can be done. ${ }^{1}$ It cannot be done arbitrarily, as the following example shows.

Example 4.2. Consider the 10 -voter profile $R^{N}$ given by

\begin{tabular}{lll}
3 & 3 & 4 \\
\hline$a$ & $b$ & $c$ \\
$b$ & $c$ & $a$ \\
$c$ & $a$ & $b$
\end{tabular}

of Example 3.3. Then $H\left(R^{N}\right)=\{b, c\}$. Suppose that $F\left(R^{N}\right)=b$. Adding a voter with ranking $R^{\prime}=b a c$ results in the following 11-voter profile $\left(R^{N}, R^{\prime}\right)$ :

\begin{tabular}{llll}
3 & 3 & 4 & 1 \\
\hline$a$ & $b$ & $c$ & $b$ \\
$b$ & $c$ & $a$ & $a$ \\
$c$ & $a$ & $b$ & $c$
\end{tabular}

Now $m_{a}\left(R^{N}, R^{\prime}\right)=m_{b}\left(R^{N}, R^{\prime}\right)=m_{c}\left(R^{N}, R^{\prime}\right)=3$, so that $H\left(R^{N}, R^{\prime}\right)=$ $\{a, b, c\}$. However, if we wish $F$ to satisfy TP, we must have $F\left(R^{N}, R^{\prime}\right)=b$.

\footnotetext{
${ }^{1}$ Clearly, Proposition 4.1 remains true if we add BP, but not if we replace TP by BP. For instance, we may select from $Y$ in Example 3.11 without always selecting from $H$.
} 
A general characterization of all selections from $H$ that satisfy CC and TP and/or BP is yet out of reach. However, we will exhibit some possibilities and impossibilities in the remainder of this section.

\subsection{Selecting independently}

We discuss selections from $H$ that are independent of the underlying rankings and only depend on the alternatives chosen by $H$. More precisely, we consider the following property for a selection $F$ from a correspondence $C$.

Independence of Irrelevant Alternatives (IIA) For all profiles $R^{N} \in L^{N}$ and $Q^{M} \in L^{M}$, if $C\left(Q^{M}\right) \subseteq C\left(R^{N}\right)$ and $F\left(R^{N}\right) \in C\left(Q^{M}\right)$, then $F\left(Q^{M}\right)=$ $F\left(R^{N}\right)$. $C^{2}$

If this condition is satisfied, then we say that $F$ satisfies IIA with respect to

Call a voting correspondence $C$ surjective if for every $\emptyset \neq B \subseteq A$ there is a profile $R^{N}$ such that $C\left(R^{N}\right)=B$. We now have the following characterization of IIA - see the Appendix for the proof. ${ }^{3}$

Proposition 4.3. Let voting correspondence $C$ be surjective and let voting function $F$ be a selection from $C$. Then $F$ satisfies IIA with respect to $C$ if and only if there is a $Q \in L$ such that $F\left(R^{N}\right) Q x$ for all $x \in C\left(R^{N}\right)$.

In other words, IIA is equivalent to choosing according to a fixed ranking $Q$ if the voting correspondence is surjective. The latter is true for any voting correspondence that is Condorcet Consistent:

Lemma 4.4. Let voting correspondence $C$ satisfy $C C$. Then $C$ is surjective.

Proof. Let $\emptyset \neq B=\left\{x_{1}, \ldots, x_{k}\right\} \subseteq A$. Let $R^{1}, R^{2} \in L$ such that $x_{1} R^{1} \ldots R^{1} x_{k}$ $R^{1} x$ and $x_{k} R^{2} \ldots R^{2} x_{1} R^{2} x$ for all $x \in A \backslash B$. Then $\mathcal{C}\left(R^{1}, R^{2}\right)=B$, so that $C\left(R^{1}, R^{2}\right)=B$ by CC of $C$.

Remark 4.5. Note that we could have used a profile with any even number of voters in the proof Lemma 4.4. For an odd number of voters, however, it is not difficult to see that a Condorcet winner, if it exists, is unique and strong, since the resistance against any alternative is also odd in that case (cf. Remark 2.1).

Our first result about voting functions satisfying $\mathrm{CC}$, TP and BP is as follows.

Proposition 4.6. Every selection $F$ from $M$ that satisfies IIA with respect to $M$, satisfies $T P$ and $B P$.

\footnotetext{
${ }^{2}$ IIA is the name usually employed for Assumption 7 in Nash (1950).

${ }^{3}$ IIA is equivalent to the Weak Axiom of Revealed Preference, and Proposition 4.3 is a familiar result stating that $F$ can be rationalized by a linear ordering.
} 
Proof. Let $F$ be a selection from $M$ satisfying IIA with respect to $M$.

First, we show that $F$ satisfies TP. Let $R^{N} \in L^{N}, x=F\left(R^{N}\right)$, and $R^{\prime} \in L$ with $t\left(R^{\prime}\right)=x$. By IIA of $F$ with respect to $M$, it is sufficient to show that $M\left(R^{N}, R^{\prime}\right) \subseteq M\left(R^{N}\right)$ and $x \in M\left(R^{N}, R^{\prime}\right)$. Let $y \in A$ with $y \notin M\left(R^{N}\right)$. Then $m_{y}\left(R^{N}\right)>m_{x}\left(R^{N}\right)$. Hence $m_{y}\left(R^{N}, R^{\prime}\right) \geq m_{y}\left(R^{N}\right)-1>m_{x}\left(R^{N}\right)-1=$ $m_{x}\left(R^{N}, R^{\prime}\right)$, so that $y \notin M\left(R^{N}, R^{\prime}\right)$. Thus, $M\left(R^{N}, R^{\prime}\right) \subseteq M\left(R^{N}\right)$. Further, for every $z \in A, m_{x}\left(R^{N}, R^{\prime}\right)=m_{x}\left(R^{N}\right)-1 \leq m_{z}\left(R^{N}\right)-1 \leq m_{z}\left(R^{N}, R^{\prime}\right)$, so that $x \in M\left(R^{N}, R^{\prime}\right)$.

Second, we show that $F$ satisfies BP. Suppose that $R^{N} \in L^{N}$ and $x \in A$ and $F\left(R^{N}\right) \neq x$. Then $M\left(R^{N}\right) \backslash\{x\} \neq \emptyset$. Let $R^{\prime} \in L$ such that $b\left(R^{\prime}\right)=x$. We show that $F\left(R^{N}, R^{\prime}\right) \neq x$. For all $y \in M\left(R^{N}\right) \backslash\{x\}$ we have

$$
m_{x}\left(R^{N}, R^{\prime}\right)=m_{x}\left(R^{N}\right)+1 \geq m_{y}\left(R^{N}\right)+1 \geq m_{y}\left(R^{N}, R^{\prime}\right) .
$$

If $x \notin M\left(R^{N}\right)$, then the first inequality in (1) is strict, hence $x \notin M\left(R^{N}, R^{\prime}\right)$, and in that case $F\left(R^{N}, R^{\prime}\right) \neq x$. If $x \in M\left(R^{N}\right) \cap M\left(R^{N}, R^{\prime}\right)$ then all inequalities in (1) are equalities, implying $M\left(R^{N}\right) \subseteq M\left(R^{N}, R^{\prime}\right)$, so that $F\left(R^{N}, R^{\prime}\right) \neq x$ by IIA.

Thus, selections from the Minimax Rule according to a fixed ranking (cf. Lemma 4.4 and Proposition 4.3) prevent both no show paradoxes considered in this paper. It turns out, however, that - if there are at least three alternatives - we cannot select independently from $H$ and still have TP or BP.

Proposition 4.7. Let $|A| \geq 3$ and let voting function $F$ be a selection from $H$ that satisfies IIA with respect to $H$. Then $F$ does not satisfy TP and $F$ does not satisfy BP.

Proof. By Lemma 4.4 and Proposition 4.3 there is a ranking $Q \in L$ such that $F\left(R^{N}\right) Q x$ for all $x \in H\left(R^{N}\right)$, for every profile $R^{N}$. Let $Q=a b c \ldots$ for some $a, b, c \in A$ and consider the following 10 -voter profile $R^{N}$, similar to the one in Example 3.3:

\begin{tabular}{ccc}
3 & 3 & 4 \\
\hline$a$ & $b$ & $c$ \\
$b$ & $c$ & $a$ \\
$c$ & $a$ & $b$ \\
$\vdots$ & $\vdots$ & $\vdots$
\end{tabular}

Then $H\left(R^{N}\right)=\{b, c\}$. Adding a voter with ranking $R^{\prime}=b a c \ldots$ results in the profile $\left(R^{N}, R^{\prime}\right)$ given by

\begin{tabular}{cccc}
3 & 3 & 4 & 1 \\
\hline$a$ & $b$ & $c$ & $b$ \\
$b$ & $c$ & $a$ & $a$ \\
$c$ & $a$ & $b$ & $c$ \\
$\vdots$ & $\vdots$ & $\vdots$ & $\vdots$
\end{tabular}

with $H\left(R^{N}, R^{\prime}\right)=\{a, b, c\}$ and thus $F\left(R^{N}, R^{\prime}\right)=a$, violating TP. 
To exhibit a violation of BP, consider the 10 -voter profile $\widetilde{R}^{N}$ given by

\begin{tabular}{ccc}
3 & 3 & 4 \\
\hline$c$ & $a$ & $b$ \\
$a$ & $b$ & $c$ \\
$b$ & $c$ & $a$ \\
$\vdots$ & $\vdots$ & $\vdots$
\end{tabular}

so that $H\left(\widetilde{R}^{N}\right)=\{a, b\}$ and $F\left(\widetilde{R}^{N}\right)=a$. Adding a voter with ranking $\check{R}=$ $c a \ldots b$ results in the profile $\left(\widetilde{R}^{N}, \breve{R}\right)$ given by

\begin{tabular}{cccc}
3 & 3 & 4 & 1 \\
\hline$c$ & $a$ & $b$ & $c$ \\
$a$ & $b$ & $c$ & $a$ \\
$b$ & $c$ & $a$ & $\vdots$ \\
$\vdots$ & $\vdots$ & $\vdots$ & $b$
\end{tabular}

so that $H\left(\widetilde{R}^{N}, \check{R}\right)=\{b, c\}$ and $F\left(\widetilde{R}^{N}, \check{R}\right)=b$, a violation of BP since $b=$ $b(\check{R})$.

\subsection{Non-independent selections}

According to Proposition 4.6, independent (IIA) selections from $M$ satisfy TP and BP. We now provide examples of selections from $M$ that satisfy TP but not BP, and conversely. Consequently, those selections cannot be achieved by maximizing according to a fixed ranking. (See the Appendix for the proofs of the claims in this subsection.)

Example 4.8. Define the voting correspondence $\bar{M}$ by

$$
\begin{aligned}
\bar{M}\left(R^{N}\right)= & \left\{x \in M\left(R^{N}\right):\left|\left\{i \in N: b\left(R^{i}\right)=x\right\}\right|\right. \\
& \left.\leq\left|\left\{i \in N: b\left(R^{i}\right)=y\right\}\right| \text { for all } y \in M\left(R^{N}\right)\right\}
\end{aligned}
$$

for every profile $R^{N}$. Hence $\bar{M}\left(R^{N}\right)$ contains those alternatives from $M\left(R^{N}\right)$ that are ranked last by a minimal number of voters. We fix a ranking $Q \in L$ and define the selection $\bar{F}$ from $\bar{M}$ such that, for every profile $R^{N}, \bar{F}\left(R^{N}\right) Q y$ for all $y \in \bar{M}\left(R^{N}\right)$ if $|N|$ is even, and $y Q \bar{F}\left(R^{N}\right)$ for all $y \in \bar{M}\left(R^{N}\right)$ if $|N|$ is odd. Then $\bar{F}$ satisfies BP but not TP.

Example 4.9. Define the voting correspondence $\check{M}$ by

$$
\begin{aligned}
\check{M}\left(R^{N}\right)= & \left\{x \in M\left(R^{N}\right):\left|\left\{i \in N: b\left(R^{i}\right)=x\right\}\right|\right. \\
& \left.\geq\left|\left\{i \in N: b\left(R^{i}\right)=y\right\}\right| \text { for all } y \in M\left(R^{N}\right)\right\}
\end{aligned}
$$

for every profile $R^{N}$. Fix a ranking $Q \in L$ and define the selection $\check{F}$ from $\check{M}$ such that, for every profile $R^{N}, \check{F}\left(R^{N}\right) Q y$ for all $y \in \check{M}\left(R^{N}\right)$. Then $\check{F}$ satisfies TP but not BP. 
Proposition 4.7 states that independent selections from $H$ cannot satisfy TP or BP. Nevertheless, there exist selections from $H$ that are not selections from $M$ and that satisfy TP and BP; TP but not BP; or BP but not TP. The following examples show this. (The proofs are in the Appendix.)

Example 4.10. Let $A=\{a, b, c\}$, consider again the first profile given in Example 3.3:

\begin{tabular}{ccc}
3 & 3 & 4 \\
\hline$a$ & $b$ & $c$ \\
$b$ & $c$ & $a$ \\
$c$ & $a$ & $b$
\end{tabular}

and call this profile $R^{*}$. Let $Q=b a c \in L$ and for every profile $R^{N} \neq R^{*}$ define $F\left(R^{N}\right) \in M\left(R^{N}\right)$ such that $F\left(R^{N}\right) Q x$ for all $x \in M\left(R^{N}\right) \backslash\left\{F\left(R^{N}\right)\right\}$; and let $F\left(R^{*}\right)=b \in H\left(R^{*}\right)=\{b, c\}$. Note that $b \notin\{c\}=M\left(R^{*}\right)$. This voting function $F$ satisfies both TP and BP.

Example 4.11. Let $A=\{a, b, c\}$, consider again the profile $R^{*}$ of Example 4.10, let now $Q=b c a \in L$, and define $F$ as in Example 4.10, now using this $Q$. Then $F$ satisfies TP but not BP.

Example 4.12. Let $A=\{a, b, c\}$, consider again the profile $R^{*}$ of Example 4.10, and let now $Q=c a b \in L$. Define $\bar{F}\left(R^{N}\right)$ as in Example 4.8 for every profile $R^{N} \neq R^{*}$, and let $F\left(R^{*}\right)=b$. Then $\bar{F}$ satisfies BP but not TP.

\section{Concluding remarks}

We have provided a necessary condition for a voting correspondence to satisfy Condorcet Consistency while at the same time ruling out the two strong no show paradoxes, namely that it should be a subcorrespondence of $H$. The basic idea leading to the definition of $H$ is that by adding additional voters Condorcet winners may pop up expelling existing winners - the condition defining $H$ rules out exactly this. A remaining problem is to find sufficient conditions for voting correspondences to satisfy these properties. Also, the construction of all selections from $H$, i.e., voting functions, that choose a Condorcet winner if there is one and rule out the strong no show paradoxes, is an open problem.

\section{A Remaining proofs}

Proof of Proposition 3.2. If $\mathcal{C}\left(R^{N}\right) \neq \emptyset$ for some profile $R^{N}$, then by Remark 2.1 either there is a unique alternative $x$ with $m_{x}\left(R^{N}\right)<0$, in which case $M\left(R^{N}\right)=\mathcal{C}\left(R^{N}\right)=\{x\}$, or $\mathcal{C}\left(R^{N}\right)=\left\{x \in A: m_{x}\left(R^{N}\right)=0\right\}$, in which case $M\left(R^{N}\right)=\mathcal{C}\left(R^{N}\right)=\left\{x \in A: m_{x}\left(R^{N}\right)=0\right\}$. Hence, $M$ satisfies CC.

Next we show that $M$ satisfies TP. Let $x \in M\left(R^{N}\right)$. Then $m_{x}\left(R^{N}\right) \leq$ $m_{y}\left(R^{N}\right)$ for all $y \in A$. Consider a ranking $R^{\prime} \in L$ such that $t\left(R^{\prime}\right)=x$. Then 
$m_{x}\left(R^{N}, R^{\prime}\right)=m_{x}\left(R^{N}\right)-1$ and $m_{y}\left(R^{N}, R^{\prime}\right) \geq m_{y}\left(R^{N}\right)-1$ for all $y \in A \backslash\{x\}$. Hence $m_{x}\left(R^{N}, R^{\prime}\right) \leq m_{y}\left(R^{N}, R^{\prime}\right)$ for all $y \in A$, so that $x \in M\left(R^{N}, R^{\prime}\right)$.

It remains to show that $M$ satisfies BP. Suppose $x \notin M\left(R^{N}\right)$. Choose $y \in A$ with $m_{x}\left(R^{N}\right)>m_{y}\left(R^{N}\right)$. Consider a ranking $R^{\prime} \in L$ such that $b\left(R^{\prime}\right)=x$. Then $m_{x}\left(R^{N}, R^{\prime}\right)=m_{x}\left(R^{N}\right)+1$ and $m_{y}\left(R^{N}, R^{\prime}\right) \leq m_{y}\left(R^{N}\right)+1$. Hence, $m_{x}\left(R^{N}, R^{\prime}\right)>m_{y}\left(R^{N}, R^{\prime}\right)$, so that $x \notin M\left(R^{N}, R^{\prime}\right)$.

Proof of Proposition 4.1. Let $R^{N} \in L^{N}$ and suppose that $x=F\left(R^{N}\right) \notin$ $H\left(R^{N}\right)$. We derive a contradiction. Since $x \notin H\left(R^{N}\right)$, there is a $y \in A$ such that $m_{y}\left(R^{N}\right)<m_{x}\left(R^{N}\right)$ and $n_{y x}\left(R^{N}\right) \geq m_{y}\left(R^{N}\right)$. If $m_{y}\left(R^{N}\right) \leq 0$ then by CC of $F$ and Remark 2.1 either $x=y$ or $m_{y}\left(R^{N}\right)=m_{x}\left(R^{N}\right)=0$, but each case contradicts $m_{y}\left(R^{N}\right)<m_{x}\left(R^{N}\right)$. Therefore $m_{y}\left(R^{N}\right)>0$. Hence, $n_{y x}\left(R^{N}\right)>0$. Equivalently, $n_{x y}<0$, which implies that $m_{y}\left(R^{N}\right)=n_{\widetilde{x} y}\left(R^{N}\right)$ for some $\widetilde{x} \in A \backslash$ $\{x\}$, i.e., $x$ does not have the maximal resistance against $y$ at the profile $R^{N}$. Let $R^{\prime} \in L$ such that $x R^{\prime} y R^{\prime} z$ for all $z \in A \backslash\{x, y\}$. Then $m_{x}\left(R^{N}, R^{\prime}\right)=m_{x}\left(R^{N}\right)-1$ and $m_{y}\left(R^{N}, R^{\prime}\right)=m_{y}\left(R^{N}\right)-1$. Thus, we still have $m_{y}\left(R^{N}, R^{\prime}\right)<m_{x}\left(R^{N}, R^{\prime}\right)$, and $n_{y x}\left(R^{N}, R^{\prime}\right)=n_{y x}\left(R^{N}\right)-1 \geq m_{y}\left(R^{N}\right)-1=m_{y}\left(R^{N}, R^{\prime}\right)$. Therefore, if we keep on adding the ranking $R^{\prime}$, then $n_{y x}\left(R^{N}, R^{\prime}, \ldots, R^{\prime}\right)$ decreases but still $n_{y x}\left(R^{N}, R^{\prime}, \ldots, R^{\prime}\right) \geq m_{y}\left(R^{N}, R^{\prime}, \ldots, R^{\prime}\right)$. Hence, after adding $m_{y}\left(R^{N}\right)$ rankings $R^{\prime}$ we have $m_{y}\left(R^{N}, R^{\prime}, \ldots, R^{\prime}\right)=0$ while $m_{x}\left(R^{N}, R^{\prime}, \ldots, R^{\prime}\right)>$ $m_{y}\left(R^{N}, R^{\prime}, \ldots, R^{\prime}\right)$. Hence $\mathcal{C}\left(R^{N}, R^{\prime}, \ldots, R^{\prime}\right) \neq \emptyset$ but $x \notin \mathcal{C}\left(R^{N}, R^{\prime}, \ldots, R^{\prime}\right)$, so that by CC of $F, x \neq F\left(R^{N}, R^{\prime}, \ldots, R^{\prime}\right)$. This violates TP of $C$.

Proof of Proposition 4.3. Suppose that $F$ satisfies IIA with respect to $C$. We construct a ranking $Q$ as in the proposition. First, take $N^{1} \subseteq \mathbb{N}$ and $R_{1}^{N^{1}} \in L^{N^{1}}$ such that $C\left(R_{1}^{N^{1}}\right)=A$. Then let $F\left(R_{1}^{N^{1}}\right) Q x$ for all $x \in A \backslash\left\{F\left(R_{1}^{N^{1}}\right)\right\}$. Next, take $N^{2} \subseteq \mathbb{N}$ and $R_{2}^{N^{2}} \in L^{N^{2}}$ such that $C\left(R_{2}^{N^{2}}\right)=A \backslash\left\{F\left(R_{1}^{N^{1}}\right)\right\}$ and let $F\left(R_{2}^{N^{2}}\right) Q x$ for all $x \in A \backslash\left\{F\left(R_{1}^{N^{1}}\right), F\left(R_{2}^{N^{2}}\right)\right\}$. Continuing this way, we construct a sequence $R_{1}^{N^{1}}, \ldots, R_{|A|-1}^{N^{|A|-1}}$ and a ranking $Q \in L$. Now let $\widetilde{R}^{M}$ be an arbitrary profile and write $B=C\left(\widetilde{R}^{M}\right)$. Let $b \in B$ such that $b Q x$ for all $x \in B$. Then let $D=\{x: b Q x$ for all $x \in A\}$ and $R_{j}^{N^{j}}$ for some $1 \leq j \leq|A|-1$ such that $C\left(R_{j}^{N^{j}}\right)=D$ then, by construction of $Q, F\left(R_{j}^{N^{j}}\right)=b$. By IIA, $F\left(\widetilde{R}^{M}\right)=b$. This shows the only-if direction of the proposition.

For the if-direction, suppose there is a ranking $Q \in L$ such that $F\left(R^{N}\right) Q x$ for every profile $R^{N}$ and every $x \in C\left(R^{N}\right)$. Suppose that $R^{N}$ and $\widetilde{R}^{M}$ are profiles with $C\left(\widetilde{R}^{M}\right) \subseteq C\left(R^{N}\right)$ and $F\left(R^{N}\right) \in C\left(\widetilde{R}^{M}\right)$. Then, since $F\left(R^{N}\right) Q x$ for all $x \in C\left(R^{N}\right)$, it follows that $F\left(R^{N}\right) Q x$ for all $x \in C\left(\widetilde{R}^{M}\right)$. Hence, $F\left(R^{N}\right)=$ $F\left(\widetilde{R}^{M}\right)$.

Proof of the claims in Example 4.8 We first show that $\bar{F}$ satisfies BP. Let $x \in A$ and $R^{N} \in L^{N}$ such that $\bar{F}\left(R^{N}\right) \neq x$. Let $R^{\prime} \in L$ with $b\left(R^{\prime}\right)=x$. We have to show that $\bar{F}\left(R^{N}, R^{\prime}\right) \neq x$. We will use the notation $\beta_{z}\left(\widetilde{R}^{P}\right)=\mid\{i \in P$ : $\left.b\left(\widetilde{R}^{i}\right)=z\right\} \mid$ for a profile $\widetilde{R}^{P}$ and an alternative $z \in A$.

If $x \notin \bar{M}\left(R^{N}, R^{\prime}\right)$ then $\bar{F}\left(R^{N}, R^{\prime}\right) \neq x$ and we are done. Thus, we assume $x \in \bar{M}\left(R^{N}, R^{\prime}\right)$. This implies, in particular, that $x \in M\left(R^{N}\right)$, since otherwise $x \notin M\left(R^{N}, R^{\prime}\right)$, hence $x \notin \bar{M}\left(R^{N}, R^{\prime}\right)$. 
Now suppose $y \in \bar{M}\left(R^{N}\right), y \neq x$. Then $m_{y}\left(R^{N}, R^{\prime}\right) \leq m_{y}\left(R^{N}\right)+1=$ $m_{x}\left(R^{N}\right)+1=m_{x}\left(R^{N}, R^{\prime}\right)$, so that $y \in M\left(R^{N}, R^{\prime}\right)$. Also, $\beta_{y}\left(R^{N}\right) \leq \beta_{x}\left(R^{N}\right)$ implies $\beta_{y}\left(R^{N}, R^{\prime}\right)=\beta_{y}\left(R^{N}\right)<\beta_{x}\left(R^{N}\right)+1=\beta_{x}\left(R^{N}, R^{\prime}\right)$. This together with $y \in M\left(R^{N}, R^{\prime}\right)$ and $x \in \bar{M}\left(R^{N}, R^{\prime}\right)$ gives a contradiction. Therefore, $\bar{M}\left(R^{N}\right)=\{x\}$, which contradicts $\bar{F}\left(R^{N}\right) \neq x$.

To show, finally, that $\bar{F}$ does not satisfy TP, we exhibit an example. Let $A=\{a, b, c\}$ and take $Q=a b c$. Consider the 6 -voter profile $R^{N}$ given by

\begin{tabular}{ccc}
2 & 2 & 2 \\
\hline$a$ & $b$ & $c$ \\
$b$ & $c$ & $a$ \\
$c$ & $a$ & $b$
\end{tabular}

Then $M\left(R^{N}\right)=\bar{M}\left(R^{N}\right)=\{a, b, c\}$ and $\bar{F}\left(R^{N}\right)=a$. For the 7 -voter profile $\left(R^{N}, R^{\prime}\right)$ with $R^{\prime}=a c b$ :

\begin{tabular}{cccc}
2 & 2 & 2 & 1 \\
\hline$a$ & $b$ & $c$ & $a$ \\
$b$ & $c$ & $a$ & $c$ \\
$c$ & $a$ & $b$ & $b$
\end{tabular}

we obtain $M\left(R^{N}, R^{\prime}\right)=\bar{M}\left(R^{N}, R^{\prime}\right)=\{a, c\}$ and $\bar{F}\left(R^{N}, R^{\prime}\right)=c$, hence a violation of TP.

Proof of the claims in Example 4.9 We first prove TP of $\check{F}$. Let $R^{N}$ be a profile with $x=\check{F}\left(R^{N}\right)$ and let $R^{\prime} \in L$ with $t\left(R^{\prime}\right)=x$. We have to show that $\check{F}\left(R^{N}, R^{\prime}\right)=x$.

If $y \in A \backslash M\left(R^{N}\right)$ then $m_{y}\left(R^{N}\right)>m_{x}\left(R^{N}\right)$, hence $m_{y}\left(R^{N}, R^{\prime}\right) \geq m_{y}\left(R^{N}\right)-$ $1>m_{x}\left(R^{N}\right)-1=m_{x}\left(R^{N}, R^{\prime}\right)$, so that $y \notin M\left(R^{N}, R^{\prime}\right)$. Hence, $M\left(R^{N}, R^{\prime}\right) \subseteq$ $M\left(R^{N}\right)$.

We claim that $\check{M}\left(R^{N}, R^{\prime}\right) \subseteq \check{M}\left(R^{N}\right)$. To prove this, let $z \in A \backslash \check{M}\left(R^{N}\right)$. We show that $z \notin \check{M}\left(R^{N}, R^{\prime}\right)$. If $z \notin M\left(R^{N}, R^{\prime}\right)$, then $z \notin \check{M}\left(R^{N}, R^{\prime}\right)$ and we are done. Now suppose $z \in M\left(R^{N}, R^{\prime}\right)$, hence also $z \in M\left(R^{N}\right)$ by the preceding paragraph. If $b\left(R^{\prime}\right)=z$ then $m_{z}\left(R^{N}, R^{\prime}\right)=m_{z}\left(R^{N}\right)+1=m_{x}\left(R^{N}\right)+1>$ $m_{x}\left(R^{N}\right)-1=m_{x}\left(R^{N}, R^{\prime}\right)$, so that $z \notin M\left(R^{N}, R^{\prime}\right)$, a contradiction. Hence $b\left(R^{\prime}\right) \neq z$ and therefore $\beta_{z}\left(R^{N}, R^{\prime}\right)=\beta_{z}\left(R^{N}\right)<\beta_{x}\left(R^{N}\right)=\beta_{x}\left(R^{N}, R^{\prime}\right)$, where the strict inequality follows from $z \in M\left(R^{N}\right) \backslash \bar{M}\left(R^{N}\right)$ (with $\beta$-notation as in the preceding proof). Hence we have $z \in M\left(R^{N}, R^{\prime}\right) \backslash \check{M}\left(R^{N}, R^{\prime}\right)$. This concludes the proof of the claim.

Since $x$ is the maximal element of $\check{M}\left(R^{N}\right)$ according to ranking $Q$, the above claim implies that it is also the maximal element of $M\left(R^{N}, R^{\prime}\right)$ according to ranking $Q$, and therefore $\check{F}\left(R^{N}, R^{\prime}\right)=x$, as was to be proved.

To show that $\breve{F}$ does not satisfy BP we exhibit the following example of a 
12 -voter profile $R^{N}$ with set of alternatives $A=\{a, b, c, d, e\}$, and $Q=a b c d e$ :

\begin{tabular}{llllll}
4 & 1 & 1 & 1 & 1 & 4 \\
\hline$b$ & $b$ & $c$ & $c$ & $a$ & $a$ \\
$e$ & $c$ & $d$ & $d$ & $c$ & $d$ \\
$c$ & $d$ & $e$ & $e$ & $d$ & $e$ \\
$d$ & $e$ & $b$ & $a$ & $e$ & $c$ \\
$a$ & $a$ & $a$ & $b$ & $b$ & $b$
\end{tabular}

Here, $M\left(R^{N}\right)=\check{M}\left(R^{N}\right)=\{a, b\}$ and $\check{F}\left(R^{N}\right)=a$. Add a ranking $R^{\prime}=c$ deab to obtain the profile $\left(R^{N}, R^{\prime}\right)$ given by

\begin{tabular}{llllll}
4 & 1 & 1 & 2 & 1 & 4 \\
\hline$b$ & $b$ & $c$ & $c$ & $a$ & $a$ \\
$e$ & $c$ & $d$ & $d$ & $c$ & $d$ \\
$c$ & $d$ & $e$ & $e$ & $d$ & $e$ \\
$d$ & $e$ & $b$ & $a$ & $e$ & $c$ \\
$a$ & $a$ & $a$ & $b$ & $b$ & $b$
\end{tabular}

then $\check{M}\left(R^{N}, R^{\prime}\right)=\{b\}$, hence $\check{F}\left(R^{N}, R^{\prime}\right)=b$, which is a violation of BP.

Proof of the claims in Example 4.10 We first show that $F$ satisfies BP. Due to Proposition 3.2 we only have to consider cases in which (i) $b$ is not chosen but by adding a ranking with $b$ at bottom we obtain profile $R^{*}$ and (ii) the cases in which we add to $R^{*}$ a new ranking with bottom alternative $a$ or $c$.

For (i) let $N=\{1, \ldots, 9\}$ and first consider profile $R_{1}^{N}$ given by

\begin{tabular}{lll}
3 & 3 & 3 \\
\hline$a$ & $b$ & $c$ \\
$b$ & $c$ & $a$ \\
$c$ & $a$ & $b$
\end{tabular}

Then $M\left(R_{1}^{N}\right)=\{a, b, c\}$ and $F\left(R_{1}^{N}\right)=b$. Hence, this case cannot lead to a violation of $\mathrm{BP}$.

Next consider the profile $R_{2}^{N}$ as follows:

\begin{tabular}{lll}
2 & 3 & 4 \\
\hline$a$ & $b$ & $c$ \\
$b$ & $c$ & $a$ \\
$c$ & $a$ & $b$
\end{tabular}

Then $M\left(R_{2}^{N}\right)=\{c\}$ and $F\left(R_{2}^{N}\right)=c$. Now $R^{*}$ is obtained by adding the ranking $R^{\prime}=a b c$ but since $b\left(R^{\prime}\right)=c$ this does not lead to a violation of BP.

Now consider the following profile $R_{3}^{N}$ :

\begin{tabular}{ccc}
3 & 2 & 4 \\
\hline$a$ & $b$ & $c$ \\
$b$ & $c$ & $a$ \\
$c$ & $a$ & $b$
\end{tabular}


Then $M\left(R_{3}^{N}\right)=\{c\}$ and $F\left(R_{3}^{N}\right)=c$. Since $R^{*}$ is obtained by adding the ranking $R^{\prime}=b c a$, again this does not lead to a violation of BP.

For (ii), let $N=\{1, \ldots, 10\}$ and consider $R^{*}$, thus $F\left(R^{*}\right)=b$. Add a ranking $R^{\prime}$ with $b\left(R^{\prime}\right)=c$. If $b R^{\prime} a R^{\prime} c$ then $M\left(R^{*}, R^{\prime}\right)=\{a, b, c\}$ and $F\left(R^{*}, R^{\prime}\right)=b \neq c$. If $a R^{\prime} b R^{\prime} c$ then $M\left(R^{*}, R^{\prime}\right)=\{a, c\}$ and $F\left(R^{*}, R^{\prime}\right)=a \neq c$. Since $a \notin\{b, c\}=$ $H\left(R^{*}\right)$ and $H$ satisfies $\mathrm{BP}$, we do not have to consider rankings $R^{\prime}$ such that $b\left(R^{\prime}\right)=a$. We conclude that $F$ satisfies BP.

Now we show TP of $F$. As in the case of BP, first consider 9-voter profiles which may result in $R^{*}$ by adding a ranking. In the case of $R_{1}^{N}$ we have $F\left(R_{1}^{N}\right)=$ $b$ and $R^{*}$ is obtained by adding the ranking $R^{\prime}=c a b$, which does not violate TP. For $R_{2}^{N}$ we have $F\left(R_{2}^{N}\right)=c$ and $R^{*}$ is obtained by adding the ranking $R^{\prime}=a b c$, which does not violate TP. For $R_{2}^{N}$ we have $F\left(R_{3}^{N}\right)=c$ and $R^{*}$ is obtained by adding the ranking $R^{\prime}=b c a$, again no violation of TP.

Finally, consider $R^{*}$ with $F\left(R^{*}\right)=b$. Adding the ranking $R^{\prime}=b a c$ results in $M\left(R^{*}, R^{\prime}\right)=\{a, b, c\}$ and $F\left(R^{*}, R^{\prime}\right)=b$, and adding the ranking $R^{\prime}=b c a$ results in $M\left(R^{*}, R^{\prime}\right)=\{b, c\}$ and $F\left(R^{*}, R^{\prime}\right)=b$, hence no violation of TP. All other cases follow from Proposition 3.2.

Proof of the claims in Example 4.11 Let $R^{\prime}=a b c$. Then $M\left(R^{*}, R^{\prime}\right)=$ $\{a, c\}$, hence $F\left(R^{*}, R^{\prime}\right)=c$, which violates $\mathrm{BP}$ since $F\left(R^{*}\right)=b$.

The proof of TP of $F$ is similar to the proof above for Example 4.10. We have $F\left(R_{1}^{N}\right)=b$, so this cannot violate TP. For $R_{2}^{N}$ we have $F\left(R_{2}^{N}\right)=c$ and therefore adding $R^{\prime}=a b c$ to obtain $R^{*}$ cannot violate TP. For $R_{3}^{N}$ we have $F\left(R_{3}^{N}\right)=c$ and therefore adding $R^{\prime}=b c a$ to obtain $R^{*}$ cannot violate TP either. Considering $R^{*}$ and adding $R^{\prime}=b a c$ results in $M\left(R^{*}, R^{\prime}\right)=\{a, b, c\}$ and $F\left(R^{*}, R^{\prime}\right)=b$, which does not violate TP. Considering $R^{*}$ and adding $R^{\prime}=b c a$ results in $M\left(R^{*}, R^{\prime}\right)=\{b, c\}$ and $F\left(R^{*}, R^{\prime}\right)=b$, which again does not violate TP. All other cases follow from Proposition 3.2.

Proof of the claims in Example 4.12 A violation of TP is obtained by adapting the profile used for this purpose in the proof of the claims in Example 4.8. (Another violation of TP can be obtained by adding the ranking $R^{\prime}=b a c$ to $R^{*}$, since then $F\left(R^{*}, R^{\prime}\right)=a \neq b=F\left(R^{*}\right)$, see below.) In order to show BP it is by the proof of the claims in Example 4.8 again sufficient to consider the cases involving $R^{*}$. First, $F\left(R_{1}^{N}\right)=b$, which cannot lead to a violation of BP. Second, $F\left(R_{2}^{N}\right)=c$, hence adding $R^{\prime}=a b c$ to obtain $R^{*}$ does not lead to a violation of BP. Third, $F\left(R_{3}^{N}\right)=c$, hence adding $R^{\prime}=b c a$ to obtain $R^{*}$ does not lead to a violation of BP. Finally, consider $R^{*}$ with $F\left(R^{*}\right)=b$. Adding a ranking $R^{\prime}$ with $b\left(R^{\prime}\right)=a$ will result in $F\left(R^{*}, R^{\prime}\right)=c$; and adding a ranking $R^{\prime}$ with $b\left(R^{\prime}\right)=c$ will result in $F\left(R^{*}, R^{\prime}\right)=a$. Hence, no violations of $\mathrm{BP}$ occur.

\section{References}

Black D (1958) The theory of committtees and elections. Cambridge: Cambridge University Press 
Brams S, Fishburn P (1983) Paradoxes of preferential voting. Mathematics Magazine 56:207-214

Brandt F, Geist C, Peters D (2017) Optimal bounds for the no-show paradox via SAT solving. Working Paper, TU Münich

de Condorcet M (1785) Essai sur l'application de l'analyse à la probabilité des décisions rendues à la pluralité des voix. Paris: Imprimerie Royale

Duddy C (2014) Condorcet's principle and the strong no show paradoxes. Theory and Decision 77:275-285

Felsenthal DS, Nurmi H (2016) Two types of participation failure under nine voting methods in variable electorates. Public Choice 168:115-135

Felsenthal DS, Tideman N (2013) Varieties of failure of monotonicity and participation under five voting methods. Theory and Decision 75:59-77

Jimeno JL, Pérez J, García E (2009) An extension of the Moulin no show paradox for voting correspondences. Social Choice and Welfare 33:343359

Kramer GH (1977) A dynamical of political equilibrium. Journal of Economic Theory 16:310-333

Moulin H (1988) Condorcet's principle implies the no show paradox. Journal of Economic Theory 45:53-64

Nash JF (1950) The bargaining problem. Econometrica 18:155-162

Núñez M, Sanver MR (2017) Revisiting the connection between the no-show paradox and monotonicity. Mathematical Social Sciences, forthcoming

Nurmi H (2002) Voting procedures under uncertainty. Springer Verlag

Pérez J (2001) The strong no show paradoxes are a common flaw in Condorcet voting correspondences. Social Choice and Welfare 18:601-616

Simpson PB (1969) On defining areas of voter choice: Professor Tullock on stable voting. Quarterly Journal of Economics 83:478-490

van Deemen A, Vergunst NP (1998) Empirical evidence of paradoxes of voting in Dutch elections. Public Choice 97:475-490

Young HP (1977) Extending Condorcet's rule. Journal of Economic Theory $16: 335-353$ 